ARTICLE

https://doi.org/10.1038/s41467-019-11292-9

\title{
Computational and experimental demonstrations of one-pot tandem catalysis for electrochemical carbon dioxide reduction to methane
}

\author{
Haochen Zhang (1) 1,6, Xiaoxia Chang (10) 2,6, Jingguang G. Chen (1) ${ }^{3}$, William A. Goddard III (1) 4, Bingjun Xu (iD) ${ }^{2}$, \\ Mu-Jeng Cheng $\mathbb{0}^{5} \&$ Qi Lu (i) ${ }^{1}$
}

Electroreduction of carbon dioxide to hydrocarbons and oxygenates on copper involves reduction to a carbon monoxide adsorbate followed by further transformation to hydrocarbons and oxygenates. Simultaneous improvement of these processes over a single reactive site is challenging due to the linear scaling relationship of the binding strength of key intermediates. Herein, we report improved electroreduction of carbon dioxide by exploiting a one-pot tandem catalysis mechanism based on computational and electrochemical investigations. By constructing a well-defined copper-modified silver surface, adsorbed carbon monoxide generated on the silver sites is proposed to migrate to surface copper sites for the subsequent reduction to methane, which is consistent with insights gained from operando attenuated total reflectance surface enhanced infrared absorption spectroscopic investigations. Our results provide a promising approach for designing carbon dioxide electroreduction catalysts to enable one-pot reduction of products beyond carbon monoxide and formate.

\footnotetext{
${ }^{1}$ State Key Laboratory of Chemical Engineering, Department of Chemical Engineering, Tsinghua University, 100084 Beijing, China. ${ }^{2}$ Center for Catalytic Science and Technology, Department of Chemical and Biomolecular Engineering, University of Delaware, Newark, DE 19716, USA. ${ }^{3}$ Department of Chemical Engineering, Columbia University, New York, NY 10027, USA. ${ }^{4}$ Materials and Process Simulation Center, California Institute of Technology, Pasadena, CA 91125, USA. ${ }^{5}$ Department of Chemistry, National Cheng Kung University, Tainan 701, Taiwan. ${ }^{6}$ These authors contributed equally: Haochen Zhang, Xiaoxia Chang. Correspondence and requests for materials should be addressed to B.X. (email: bxu@udel.edu) or to M.-J.C. (email: mjcheng@mail.ncku.edu.tw) or to Q.L. (email: luqicheme@mail.tsinghua.edu.cn)
} 
$\mathrm{T}$ he electrochemical reduction of $\mathrm{CO}_{2}$ to energy-dense chemicals is an attractive strategy for storing the intermittent renewable electricity produced by solar and wind sources ${ }^{1-3}$. To ensure sustainability of the entire process, the electrochemical $\mathrm{CO}_{2}$ reduction reaction $\left(\mathrm{CO}_{2} \mathrm{RR}\right)$ is typically conducted in an aqueous electrolyte, in which the protons required are obtained. In this system, tremendous progress has been made in catalyst ${ }^{4-6}$ and reactor design ${ }^{7,8}$ to drive the twoelectron reduction of $\mathrm{CO}_{2}$ to produce $\mathrm{CO}$ or formate. However, strategies for direct reduction of $\mathrm{CO}_{2}$ to more valuable fuels and chemicals have been less successful because the catalysts capable of catalyzing this conversion are very limited. Only $\mathrm{Cu}$ exhibits appreciable activity and Faradaic efficiency (FE) for reducing $\mathrm{CO}_{2}$ to hydrocarbons and oxygenates ${ }^{9-11}$. The lack of predictive catalyst design principles for $\mathrm{CO}_{2} \mathrm{RR}$ limits the development of catalysts capable of directly converting $\mathrm{CO}_{2}$ to products beyond $\mathrm{CO}$ and formate

To achieve higher efficiencies in the $\mathrm{CO}_{2} \mathrm{RR}$ toward hydrocarbons and oxygenates, the most common approach involves modifying the $\mathrm{Cu}$ surface to produce and/or enrich active sites with a specific structure. These efforts include oxidation and reduction treatment to expose grain boundary-terminated $\mathrm{Cu}$ surfaces $^{12,13}$, plasma treatment ${ }^{14,15}$, and electro-redeposition ${ }^{16}$ to introduce stable $\mathrm{Cu}^{+}$species, morphology control to expose high density low-coordinated surface sites ${ }^{17,18}$, and alloying with an additional metal to tune the binding strength to the reaction intermediates ${ }^{19-22}$. Despite the recent progress, the improvement in the performance as compared to the pure $\mathrm{Cu}$ remains unsatisfactory. In particular, the selectivity of alloy catalysts toward products beyond $\mathrm{CO}$ and formate do not surpass that of pure $\mathrm{Cu}^{10,11}$. Therefore, novel approaches to design more efficient $\mathrm{CO}_{2} \mathrm{RR}$ catalysts capable of selectively producing valuable products are highly desirable.

On polycrystalline $\mathrm{Cu}$ surfaces, $\mathrm{CO}_{2}$ is first converted to adsorbed $\mathrm{CO}$ adsorbate $\left({ }^{*} \mathrm{CO}\right)$ followed by its further reduction to hydrocarbons and oxygenates. However, the optimal sites for these two processes could have quite different properties because the formation of ${ }^{*} \mathrm{CO}$ requires the optimal binding strength for ${ }^{*} \mathrm{COOH}^{23-25}$ while the formation of hydrocarbons and oxygenates requires the optimal binding strength for ${ }^{\star} \mathrm{CO}^{25-27}$. The simultaneous optimization of the binding strength of ${ }^{*} \mathrm{COOH}$ and ${ }^{*} \mathrm{CO}$ on one type of reactive site can be challenging due to the linear scaling relationship ${ }^{26}$. For example, the $\mathrm{Au}_{3} \mathrm{Cu}$ nanoparticle catalyst exhibited a very high activity for reducing $\mathrm{CO}_{2}$ to $\mathrm{CO}$. However, this catalyst was nearly incapable of producing further reduced products ${ }^{19}$. An oxide-derived $\mathrm{Cu}$ catalyst exhibited a much improved $\mathrm{FE}$ for reducing $\mathrm{CO}$ to alcohols. However, this catalyst cannot effectively and directly reduce $\mathrm{CO}_{2}$ to products beyond $\mathrm{CO}$ and formate ${ }^{12}$.

Therefore, the conversion of $\mathrm{CO}_{2}$ using tandem catalysis can be a promising strategy to improve the overall efficiencies for further reduced products. By co-locating $\mathrm{Cu}$ with a $\mathrm{CO}$-producing surface (e.g., $\mathrm{Au}$ and $\mathrm{Ag}$ ), the $\mathrm{Cu}$ may be supplied with abundant $\mathrm{CO}$ via spillover. A higher coverage of $\mathrm{CO}$ on the $\mathrm{Cu}$ surface can not only increase the rates of hydrocarbon and oxygenate production $^{28-30}$ but also suppress the competing hydrogen evolution reaction (HER) by weakening the binding strength of $H_{\mathrm{ads}}{ }^{31}$. Recently, several bimetallic surfaces including $\mathrm{Cu}-\mathrm{Zn}^{20}$ and $\mathrm{Cu}$ $\mathrm{Au}^{22}$ were investigated in the $\mathrm{CO}_{2} \mathrm{RR}$. The $\mathrm{Cu}-\mathrm{Zn}$ surface exhibited improved selectivity for ethanol over ethylene, and the $\mathrm{Cu}-\mathrm{Au}$ surface exhibited an improved partial current density toward reduction products beyond $\mathrm{CO}$ from approximately 0.005 to $0.16 \mathrm{~mA} \mathrm{~cm}^{-2}$ compared to a bare $\mathrm{Cu}$ foil at a low overpotential. A tandem catalysis mechanism was proposed to explain these improvements. However, $\mathrm{CO}$ spillover was not demonstrated in these systems. Therefore, the origin of the observed synergetic improvements remains unclear. Another recent study demonstrated that a $\mathrm{Cu}-\mathrm{Ag}$ bimetallic surface can be more selective for $\mathrm{C}_{2}$ product formation ${ }^{21}$. However, this improvement was not due to $\mathrm{CO}$ spillover but suppression of the HER from the formation of the compressively strained alloy surface. Herein we report a combined computational and experimental study of one-pot tandem catalytic $\mathrm{CO}_{2} \mathrm{RR}$. By constructing welldefined model surfaces with isolated thin $\mathrm{Cu}$ layers on a $\mathrm{CO}$ producing substrate (i.e., $\mathrm{Au}$ and $\mathrm{Ag}$ ), the $\mathrm{CO}$ produced on the $\mathrm{CO}$-producing $\mathrm{Au}$ or $\mathrm{Ag}$ would migrate to $\mathrm{Cu}$ with a low activation energy and be further reduced by $\mathrm{Cu}$. In comparison to pure $\mathrm{Cu}$, our model surface exhibited better $\mathrm{CH}_{4}$ selectivity and activity as well as suppressed HER ${ }^{10,11}$. Operando attenuated total reflectance surface enhanced infrared absorption spectroscopic (ATR-SEIRAS) investigations yielded the first spectroscopic evidence of $\mathrm{CO}$ spillover on a Cu-based bimetallic catalyst. More importantly, our results clearly demonstrate a new paradigm for the design of $\mathrm{CO}_{2} \mathrm{RR}$ catalysts to achieve further reduced products beyond $\mathrm{CO}$ and formate.

\section{Results}

Theoretical investigations of carbon monoxide spillover. Ag and $\mathrm{Au}$ are known to be the most efficient monometallic surfaces for $\mathrm{CO}$ production from the $\mathrm{CO}_{2} \mathrm{RR}^{4,5}$. Our computational investigation begins with examination of the possibility for $\mathrm{CO}$ spillover from a CO-producing $\mathrm{Ag}$ or $\mathrm{Au}$ site to a surface $\mathrm{Cu}$ site prior to further reduction. The surface is divided into eight regions along the direction from bare $\mathrm{Ag}$ (or $\mathrm{Au}$ ) sites toward surface $\mathrm{Cu}$ sites for the discussion of $\mathrm{CO}$ spillover, and only the $\Delta G_{\mathrm{CO}}$ of sites with the strongest binding energy in each region on the $\mathrm{Cu}$-added $\mathrm{Ag}$ or Au surface are considered in the $\mathrm{CO}$ spillover discussion (Fig. 1a and Supplementary Table 1). As shown in Fig. $1 \mathrm{~b},{ }^{\star} \mathrm{CO}$ adsorption is typically more stable on surface $\mathrm{Cu}$ sites than $\mathrm{Ag}$ or $\mathrm{Au}$ sites. The $\Delta \mathrm{G}_{\mathrm{CO}}$ at bare substrate sites nonadjacent to $\mathrm{Cu}$ (i.e., site nos. 1-3) exhibit similar values (i.e., $\sim 0.73 \mathrm{eV}$ for $\mathrm{Ag}$ and $\sim 0.34 \mathrm{eV}$ for $\mathrm{Au}$, respectively). As the $\mathrm{CO}$ molecule approaches the surface $\mathrm{Cu}, \Delta G_{\mathrm{CO}}$ decreases substantially (stronger adsorption) and reaches a minimum value at site no. 5 on $\mathrm{Ag}(-0.34 \mathrm{eV})$ and $\mathrm{Au}(-0.75 \mathrm{eV})$ where $\mathrm{CO}$ forms a bond with the surface $\mathrm{Cu}$ atoms. Significantly better $\mathrm{CO}$ adsorption is observed on surface $\mathrm{Cu}$ than its substrate for both $\mathrm{Ag}(1.07 \mathrm{eV})$ and $\mathrm{Au}(1.09 \mathrm{eV})$. Moreover, the free energy barrier for $\mathrm{CO}$ spillover on both surfaces is calculated to be very small (no more than $0.16 \mathrm{eV}$ ), which can be easily surmounted at room temperature (Supplementary Table 2) and is consistent with previous works ${ }^{32,33}$. Thus our computational results indicate that $\mathrm{CO}$ spillover from the $\mathrm{Ag}$ or $\mathrm{Au}$ substrate to the surface $\mathrm{Cu}$ is thermodynamically and kinetically feasible. The one-pot tandem reduction of $\mathrm{CO}_{2}$ may be viable by converting $\mathrm{CO}_{2}$ to $\mathrm{CO}$ on a $\mathrm{CO}$-producing substrate followed by $\mathrm{CO}$ spillover and further reduction on a surface $\mathrm{Cu}$ site.

Theoretical investigations of carbon monoxide reduction after spillover. The further reduction of $\mathrm{CO}$ on surface $\mathrm{Cu}$ after spillover is investigated. The conversion of $\mathrm{CO}$ to $\mathrm{C}_{1}$ products is chosen as the model reaction process for this investigation because (a) this process is less controversial and the results can be supported by previous work ${ }^{34-37}$, and (b) other processes require C-C coupling via mechanisms that are unclear and currently under debate ${ }^{38-40}$. The kinetics and thermodynamics for all possible pathways toward $\mathrm{C}_{1}$ products are calculated (Fig. 2, Supplementary Fig. 1 and Supplementary Table 3). Different from traditional calculations with a fixed electron number, the number of electrons in each calculation is adjusted to maintain a potential of $-1.0 \mathrm{~V}_{\mathrm{SHE}}$, which is more representative of experimental 
a

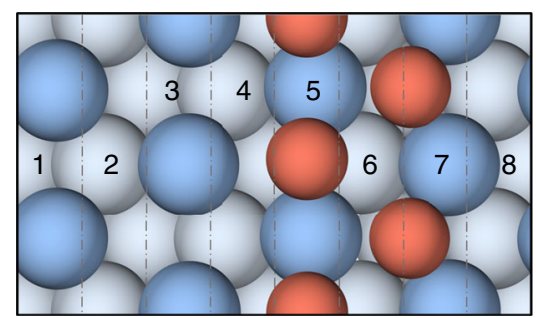

b

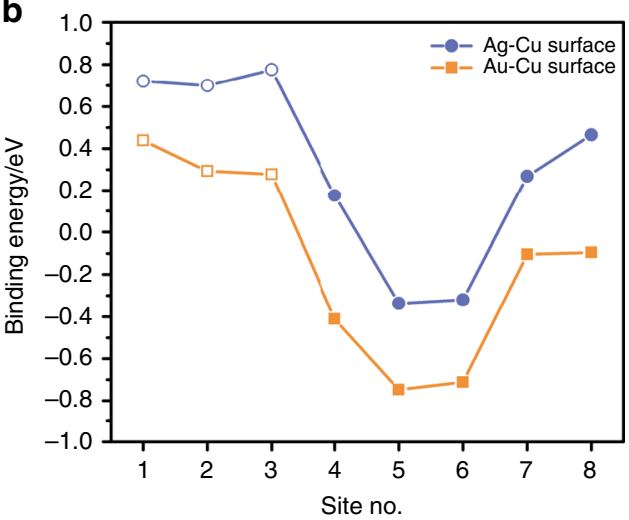

Fig. 1 Schematic diagram. The computational model is constructed by adding a single layer of $\mathrm{Cu}$ with a coverage of $1 / 2 \mathrm{ML}$ (monolayer) on top of the three-layer $\mathrm{Ag}$ or $\mathrm{Au}$ substrate. The surface $\mathrm{CO}$ adsorption is under $-1.0 \mathrm{~V}_{\mathrm{SHE}}$. The substrate orientation is chosen to be (111) because it is the most stable and abundant surface facet for bulk $\mathrm{Ag}$ or Au materials. A clean surface, $\mathrm{CO}_{2(g)}, \mathrm{H}_{2} \mathrm{O}_{(I)}$ and $\mathrm{H}_{2(g)}$ are used as references to construct the free energy surfaces. a Top view of the unit cell used for computational investigations (blue: top layer $\mathrm{Ag}$ or $\mathrm{Au}$ atoms; light blue: bottom layer $\mathrm{Ag}$ or $\mathrm{Au}$ atoms; orange: $\mathrm{Cu}$ atoms). The site numbers show the position and chemical environment of the binding sites. $\mathbf{b}$ Energy diagram for $\mathrm{CO}$ adsorption on the Ag-Cu surface (blue line) and Au-Cu surface (orange line). Data of sites nonadjacent to the surface $\mathrm{Cu}$ are shown in hollow bullets

reaction conditions. The most energetically favored pathway toward $\mathrm{CH}_{4}$ at $-1.0 \mathrm{~V}_{\mathrm{SHE}}$ is determined to be ${ }^{\star} \mathrm{CO} \rightarrow{ }^{*} \mathrm{CHO} \rightarrow$ ${ }^{\star} \mathrm{CHOH} \rightarrow{ }^{\star} \mathrm{CH} \rightarrow{ }^{\star} \mathrm{CH}_{2} \rightarrow{ }^{\star} \mathrm{CH}_{3} \rightarrow{ }^{\star}+\mathrm{CH}_{4}$ on both the $\mathrm{Ag}-\mathrm{Cu}$ and $\mathrm{Au}-\mathrm{Cu}$ surfaces (Fig. 2 and Supplementary Fig. 1). The surface $\mathrm{Cu}$ exhibits the ability to reduce $\mathrm{CO}$ to $\mathrm{CH}_{4}$ at $-1.0 \mathrm{~V}_{\mathrm{SHE}}$. As suggested by the results in Fig. 2 and Supplementary Fig. 1, the hydrogenation of ${ }^{\star} \mathrm{CO}$ to ${ }^{\star} \mathrm{CHO}$, which is the most difficult reaction among all the reaction steps, exhibits the highest free energy barrier $\left(\Delta G^{\neq}\right)$with a value of 0.57 and $0.50 \mathrm{eV}$ for the $\mathrm{Ag}$ $\mathrm{Cu}$ and $\mathrm{Au}-\mathrm{Cu}$ surfaces, respectively. All reactions along the pathway at a potential bias of $-1.0 \mathrm{~V}_{\mathrm{SHE}}$ are thermodynamically downhill and kinetically feasible with $\Delta G^{\neq}$values being $<0.75 \mathrm{eV}$, a number leading to a turnover frequency of approximately $1 \mathrm{~s}^{-1}$ at room temperature based on the transition state theory ${ }^{34,35}$. The hydrogenation of ${ }^{*} \mathrm{CH},{ }^{*} \mathrm{CH}_{2}$, and ${ }^{*} \mathrm{CH}_{3}$ exhibits no free energy barrier. Similar results were also reported by Chan et al. in the study of $\mathrm{CO}_{2}$ reduction on stepped copper ${ }^{41,42}$. This result indicates that $\mathrm{CO}$ reduction by the surface $\mathrm{Cu}$ on $\mathrm{Ag}$ or $\mathrm{Au}$ will be kinetically feasible. In contrast, pathways toward other possible $\mathrm{C}_{1}$ product methanol are kinetically unfavorable, although they are thermodynamically feasible. Accordingly, both the thermodynamics and kinetics indicate that the surface $\mathrm{Cu}$ on $\mathrm{Ag}$ or $\mathrm{Au}$ can reduce $\mathrm{CO}_{2}$ to $\mathrm{CH}_{4}$ in a one-pot tandem fashion.

Ag-Cu model surface for electrochemical study. The $\mathrm{Ag}-\mathrm{Cu}$ surface rather than the $\mathrm{Au}-\mathrm{Cu}$ surface is chosen as the model catalyst for electrochemical investigations due to the costeffectiveness of $\mathrm{Ag}$ over $\mathrm{Au}$. The $\mathrm{Cu}$-modified $\mathrm{Ag}$ surface is prepared at the beginning of $\mathrm{CO}_{2}$ electrolysis by conducting the reaction in a bicarbonate electrolyte containing a predetermined (ppm) level of $\mathrm{Cu}^{2+}$. Owing to the reduction potential of $\mathrm{Cu}^{2+}$ $\left(\mathrm{Cu}^{2+}(\mathrm{aq})+2 \mathrm{e}^{-} \rightarrow \mathrm{Cu}(\mathrm{s}) \quad\left(+0.16 \mathrm{~V}_{\mathrm{SHE}}\right.\right.$ for $\mathrm{ppm}$ level $\left.\left.\mathrm{Cu}^{2+}\right)\right)$ being significantly more positive than the electroreduction potential of $\mathrm{CO}_{2}$ (typically $<-1.3 \mathrm{~V}_{\mathrm{SHE}}$ ), the ppm-level $\mathrm{Cu}^{2+}$ is instantly electrochemically deposited onto the Ag foil when the electrolysis is initiated, making the deposition process indistinguishable during chronoamperometry. This is supported by the observation that the reduction current of $\mathrm{Cu}^{2+}$ is indistinguishable in current profiles at all potentials (Supplementary Fig. 2). Further, the surface morphologies at the early stage and at the conclusion of the electrolysis are similar (Supplementary Fig. 3). The deposited $\mathrm{Cu}$ form islands that are a few tens of nanometers in size on the Ag surface (Fig. $3 \mathrm{a}-\mathrm{c}$ ), which is consistent with previous results using a similar technique ${ }^{43}$. The coverage of surface $\mathrm{Cu}$ can be tuned by controlling the initial $\mathrm{Cu}^{2+}$ concentration in the electrolyte and is characterized using scanning electron microscopy (SEM) and X-ray photoelectron spectroscopy (XPS) (Fig. 3a-c, Table 1, Supplementary Fig. 4). The highly crystalline nature of surface $\mathrm{Cu}$ is confirmed by highresolution transmission electron microscope (HR-TEM) with samples prepared using focused ion beam technique (Supplementary Fig. 5).

The $\mathrm{CO}_{2}$ electrolysis study of these $\mathrm{Ag}-\mathrm{Cu}$ surfaces is conducted at $-1.1 \mathrm{~V}_{\mathrm{RHE}}$ because Ag foil exhibits the highest FE for CO production at this potential (Fig. 4c) ${ }^{23}$. The distribution of the major products is shown in Fig. 3d. As the $\mathrm{Cu}^{2+}$ concentration increases from 0 to $1.5 \mathrm{ppm}$, which corresponds to a $\mathrm{Cu}$ coverage increases from $0 \%$ to $50.2 \%$ (Table 1), the $\mathrm{CH}_{4}$ FE increases substantially from $0 \%$ to approximately $60 \%$, and the CO FE decreases concomitantly from $>80 \%$ to approximately $10 \%$ (Fig. 3d). The $\mathrm{CH}_{4} \mathrm{FE}$ achieved on this partially $\mathrm{Cu}$-covered $\mathrm{Ag}$-Cu surface (i.e., $\mathrm{Cu}$ coverage of $50.2 \%$ ) is much higher that on a bare polycrystalline $\mathrm{Cu}$ foil at the same potential (Supplementary Fig. 6) ${ }^{11}$. This result indicates that $\mathrm{CH}_{4}$ production on $\mathrm{Cu}$ can be efficiently improved via the prior reduction of $\mathrm{CO}_{2}$ to $\mathrm{CO}$ on a nearby $\mathrm{Ag}$ surface. Because a further increase in the $\mathrm{Cu}$ coverage decreases the $\mathrm{CH}_{4} \mathrm{FE}$, the essential role of Ag surface exposure is to provide sufficient $\mathrm{CO}$ supply to achieve a high $\mathrm{CH}_{4}$ FE. At a $\mathrm{Cu}^{2+}$ concentration of $2.5 \mathrm{ppm}$, the $\mathrm{Cu}$ coverage reaches $85.3 \%$, and the $\mathrm{CH}_{4} \mathrm{FE}$ value decreases to approximately $35 \%$, which is consistent with results obtained on a polycrystalline $\mathrm{Cu}$ foil at the same potential (Supplementary Fig. 6) ${ }^{11}$. The Ag-Cu surfaces are not very selective to $\mathrm{C}_{2} \mathrm{H}_{4}$, which is most likely due to the preferential adsorption of those ${ }^{*} \mathrm{CO}$ that migrates from the $\mathrm{Ag}$ surface on the edge of $\mathrm{Cu}$ islands where the reduced dimension may promote the exposure of low-coordinated surface sites. These low-coordinated sites may bind ${ }^{*} \mathrm{CO}$ too strongly that prevent the further movement of ${ }^{\star} \mathrm{CO}$ for dimerization.

Potential dependence study at the silver-copper surface. The $\mathrm{Ag}-\mathrm{Cu}$ surface with the optimal $\mathrm{Cu}$ coverage achieved at a $\mathrm{Cu}^{2+}$ concentration of $1.5 \mathrm{ppm}$ is employed to further investigate the one-pot tandem catalysis in the $\mathrm{CO}_{2} \mathrm{RR}$. The potential range for the electrolysis experiment is $-0.6 \mathrm{~V}_{\mathrm{RHE}}$ to $-1.3 \mathrm{~V}_{\mathrm{RHE}}$ (equivalent to $-1.0 \mathrm{~V}_{\mathrm{SHE}}$ to $-1.7 \mathrm{~V}_{\mathrm{SHE}}$ ) to drive sufficient but not excessive activities. The $\mathrm{Ag}-\mathrm{Cu}$ surface at these potentials exhibits nearly identical morphologies (Supplementary Fig. 7). This is most likely due to the large deposition overpotentials $(>1.16 \mathrm{~V})$ for only ppm-level $\mathrm{Cu}^{2+}$ in the electrolyte and the deposition processes are limited by the diffusion of $\mathrm{Cu}^{2+}$ rather than the electrode potential. This is supported by the observation in a 
Ag-Cu surface

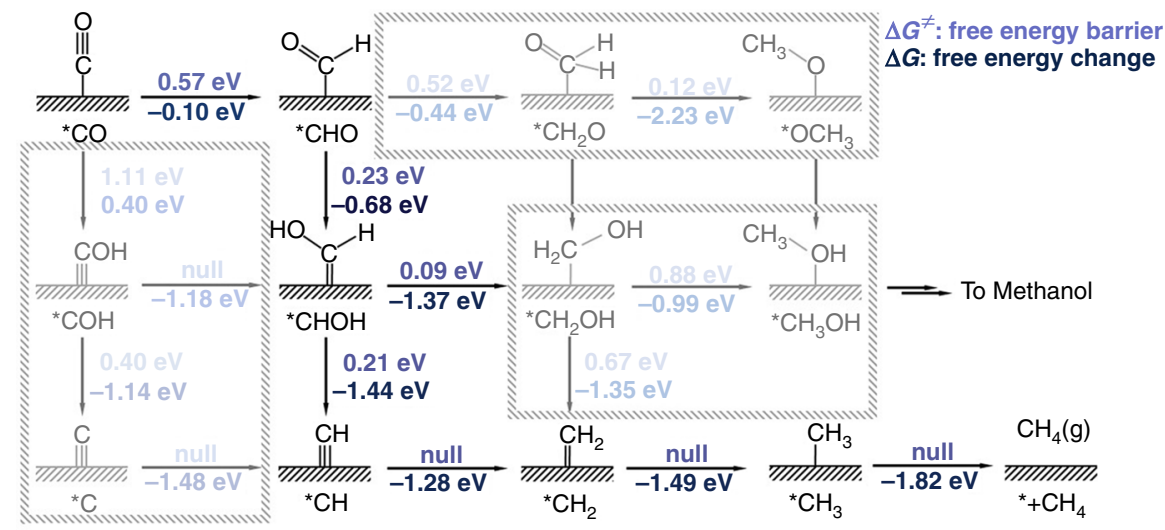

Fig. 2 Kinetics and free energy diagram for all possible pathways toward $C_{1}$ products. $C O$ is reduced to $C_{1}$ products on the $A g$ - $C u$ surface. The values shown blue (upper) and dark blue (bottom) are the free energy barrier and free energy change at $-1.0 \mathrm{~V}_{\mathrm{SHE}}$ for all steps, respectively. Adsorbates with an asterisk correspond to species that are adsorbed on the surface. Null stands for no free energy barrier
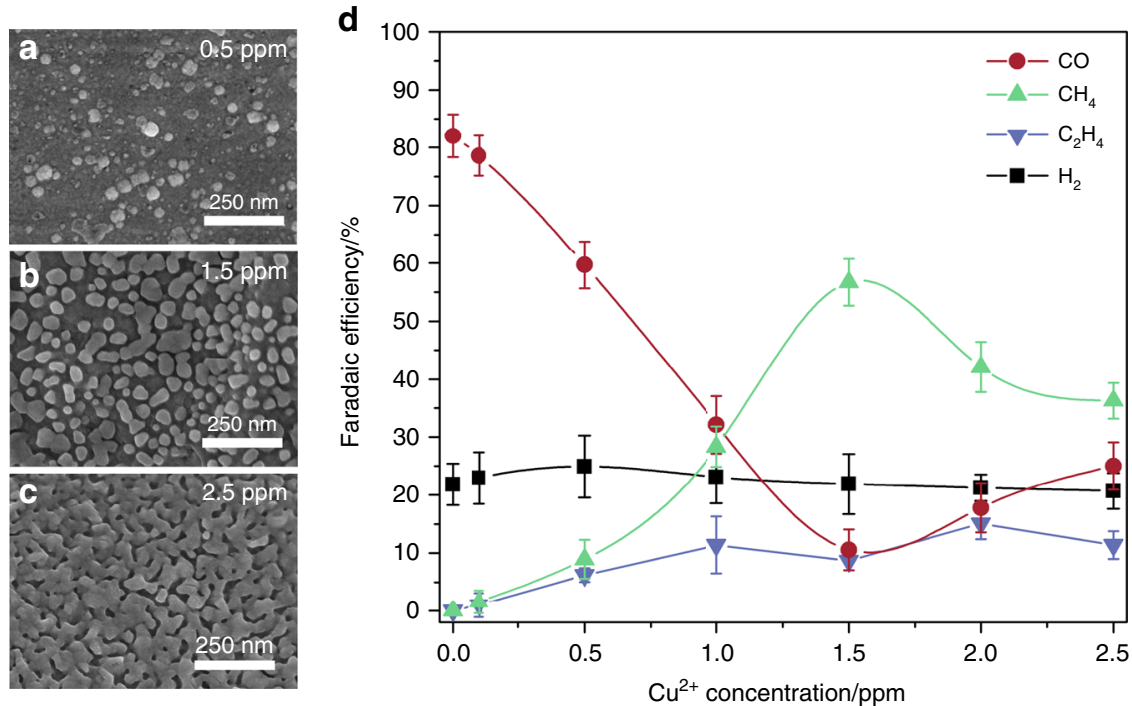

Fig. 3 Silver-copper model catalyst surface with different copper coverages. Scanning electron microscopic images of $\mathrm{Ag}$ - $\mathrm{Cu}$ surfaces achieved at $\mathrm{Cu} 2+$

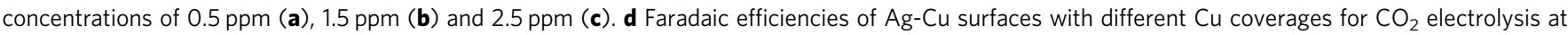
$-1.10 V_{\text {RHE. }}$. The error bars represent the standard deviation from at least three independent measurements

Table 1 Surface $\mathrm{Cu}$ coverage with different $\mathrm{Cu}^{2+}$ concentrations in the electrolyte

\begin{tabular}{lcllll}
$\mathbf{C u}^{\mathbf{2}+}$ concentration/ppm & \multicolumn{1}{c}{$\mathbf{0 . 5}$} & $\mathbf{1 . 0}$ & $\mathbf{1 . 5}$ & $\mathbf{2 . 0}$ & $\mathbf{2 . 5}$ \\
\hline Surface Cu coverage & $2.7 \%$ & $32.3 \%$ & $50.2 \%$ & $70.0 \%$ & $85.3 \%$ \\
Surface Ag coverage & $97.3 \%$ & $67.7 \%$ & $49.8 \%$ & $30.0 \%$ & $14.7 \%$
\end{tabular}

previous study that the electrodeposition of $\mathrm{Cu}$ begins to be diffusion-limited with an overpotential of $>300 \mathrm{mV}$ at a $\mathrm{Cu}^{2+}$ concentration of $0.15 \mathrm{M}^{44}$. When the overpotential is $>800 \mathrm{mV}$, such deposition process is completely diffusion-limited and the deposited $\mathrm{Cu}$ exhibits near identical morphologies ${ }^{44,45}$.

In the $-0.6 \mathrm{~V}_{\mathrm{RHE}}$ to $-1.0 \mathrm{~V}_{\mathrm{RHE}}$ potential range, the $\mathrm{Ag}-\mathrm{Cu}$ surface exhibits a similar electrocatalytic behavior as that of a bare $\mathrm{Ag}$ surface with $\mathrm{CO}$ and $\mathrm{H}_{2}$ as the major products (Fig. 4). Both the $\mathrm{CO}$ and $\mathrm{H}_{2}$ partial current densities increase as the potential becomes more negative due to the increased overpotential (Fig. 4b, d). The increase in CO production is more significant than that of $\mathrm{H}_{2}$ production, resulting in an increase in CO FE and a decrease in $\mathrm{H}_{2}$ FE (Fig. $4 \mathrm{a}-\mathrm{c}$ ). As the potential becomes more negative than $-1.0 \mathrm{~V}_{\mathrm{RHE}}$, the $\mathrm{Ag}$-Cu surface exhibits a substantial increase in the $\mathrm{CH}_{4}$ partial current density with a concomitant decrease in the CO partial current density (Fig. 4b). However, for the bare Ag surface, the $\mathrm{CO}$ partial current density continuously increases and begins to plateau at $-1.1 \mathrm{~V}_{\mathrm{RHE}}$, which is most likely due to mass transport limitations (Fig. 4d). This result clearly demonstrates that the exposed $\mathrm{Ag}$ surface on $\mathrm{Ag}$-Cu behaves very differently from the bare $\mathrm{Ag}$. If the exposed $\mathrm{Ag}$ surface merely converts $\mathrm{CO}_{2}$ to molecular $\mathrm{CO}$ that leaves the $\mathrm{Ag}$-Cu surface, as is the case for the bare Ag surface, the CO partial current density should increase as the potential becomes more negative until mass-transport limitation. In contrast, the $\mathrm{CO}$ partial current density of $\mathrm{Ag}-\mathrm{Cu}$ surface actually decreases at more negative potentials where $\mathrm{CH}_{4}$ formation starts to increase (Fig. $4 \mathrm{~b}$ ), indicating that the extra $\mathrm{CO}$ produced on exposed $\mathrm{Ag}$ sites 

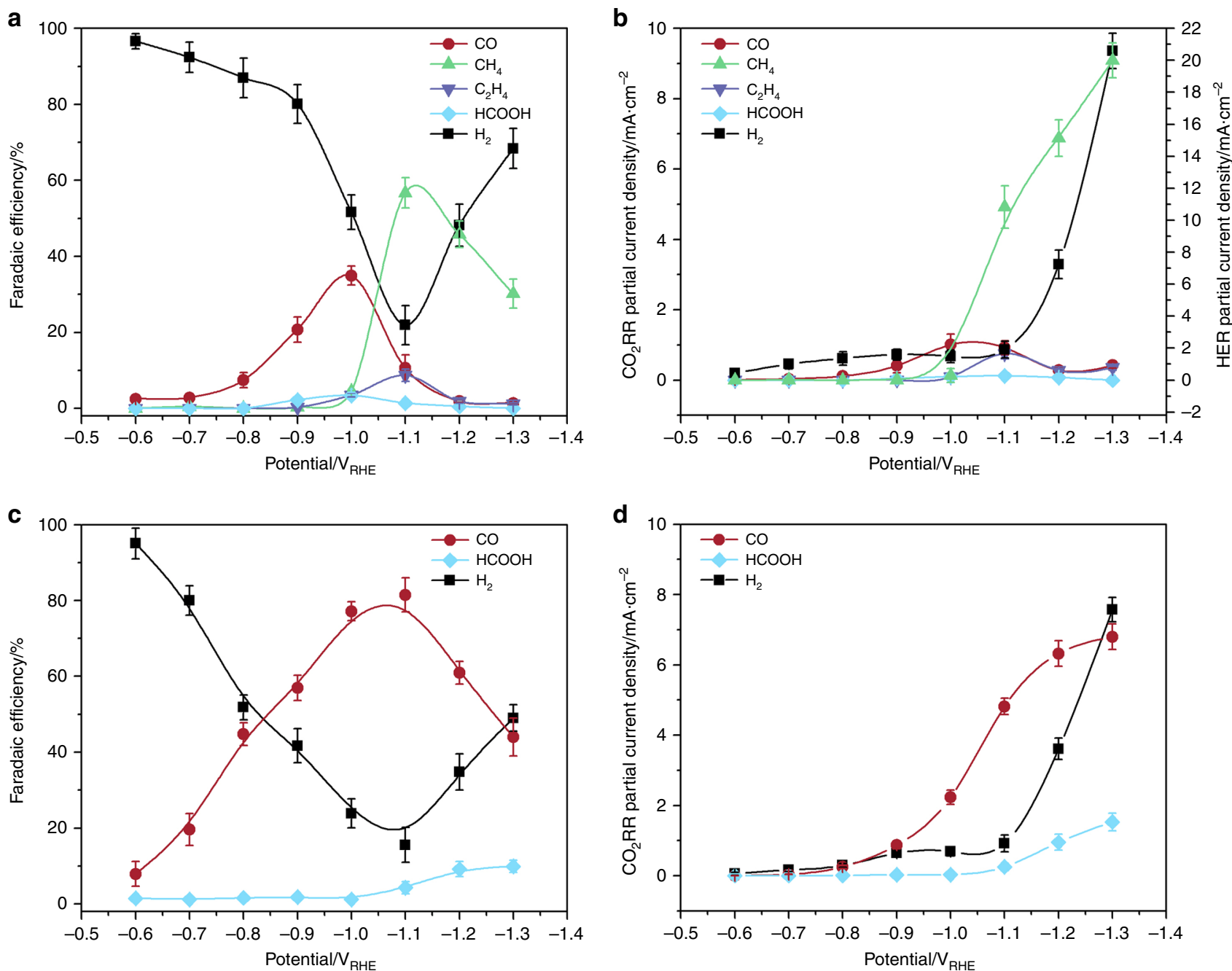

Fig. 4 Carbon dioxide electrolysis on the silver-copper and bare silver surfaces. Faradaic efficiencies (a) and partial current densities (b) of $\mathrm{CO}_{2}$ electrolysis products on the $\mathrm{Ag}-\mathrm{Cu}$ surface achieved at a $\mathrm{Cu}^{2+}$ concentration of $1.5 \mathrm{ppm}$. Faradaic efficiencies (c) and partial current densities (d) of $\mathrm{CO}_{2}$ electrolysis products on a bare polycrystalline $\mathrm{Ag}$ surface. The error bars represent the standard deviation from at least three independent measurements

beyond a potential of $-1.0 \mathrm{~V}_{\mathrm{RHE}}$ is consumed in other processes (i.e., $\mathrm{CO}$ spillover). In addition, at $-1.0 \mathrm{~V}_{\mathrm{RHE}}$, the $\mathrm{CO}$ partial current density of $\mathrm{Ag}-\mathrm{Cu}\left(1.0 \mathrm{~mA} \mathrm{~cm}^{-2}\right)$ is approximately $46 \%$ of that of the bare $\mathrm{Ag}$ surface $\left(2.2 \mathrm{~mA} \mathrm{~cm}^{-2}\right)$. This value is consistent with the $49.8 \%$ exposed $\mathrm{Ag}$ on the $\mathrm{Ag}-\mathrm{Cu}$ surface because its $\mathrm{CO}$ partial current density is primarily attributed to the exposed $\mathrm{Ag}$ due to the very low $\mathrm{CO}$ activity of $\mathrm{Cu}$ (less than $0.1 \mathrm{~mA} \mathrm{~cm}^{-2}$ at potentials more negative than $\left.-1.0 \mathrm{~V}_{\mathrm{RHE}}\right)^{11}$. As the potential decreases from $-1.0 \mathrm{~V}_{\mathrm{RHE}}$ to $-1.1 \mathrm{~V}_{\mathrm{RHE}}$, the $\mathrm{CO}$ partial current density on the bare $\mathrm{Ag}$ increases from 2.23 to 4.82 $\mathrm{mA} \mathrm{cm}{ }^{-2}$ representing a factor of 2.16 increase (Fig. 4d). However, the $\mathrm{CO}$ partial current density on the $\mathrm{Ag}-\mathrm{Cu}$ surface decreases slightly from 1.0 to $0.9 \mathrm{~mA} \mathrm{~cm}^{-2}$ under the same condition (Fig. 4b), assuming that the $\mathrm{Ag}$ sites on the $\mathrm{Ag}-\mathrm{Cu}$ surface would produce more $\mathrm{CO}$ with the same factor of 2.16 and the missing portion (i.e., $1.26 \mathrm{~mA} \mathrm{~cm}^{-2}$ ) is further converted to $\mathrm{CH}_{4}$ by the surface $\mathrm{Cu}$. The $\mathrm{CH}_{4}$ partial current density can be estimated to be $5.04 \mathrm{~mA} \mathrm{~cm}^{-2}\left(1.26 \mathrm{~mA} \mathrm{~cm}^{-2} \times 4\right)$ since $\mathrm{CH}_{4}$ production requires four times as many electrons as $\mathrm{CO}$ production. Indeed, this value is consistent with the experimentally measured value (i.e., $4.9 \mathrm{~mA} \mathrm{~cm}^{-2}$ ). This result indicates that, at the optimal Cu coverage, nearly $60 \%$ of the CO produced on $\mathrm{Ag}$ is further reduced to $\mathrm{CH}_{4}$ on the $\mathrm{Cu}$ surface via the tandem process. At more negative potentials, significant HER activity is observed on both surfaces, which results in the decreased $\mathrm{FE}$ of $\mathrm{CO}_{2} \mathrm{RR}$. The drastically increased HER activity on the Ag- $\mathrm{Cu}$ surface is most likely due to the rapid HER on surface $\mathrm{Cu}$ sites at high potential bias (Supplementary Fig. 6). $\mathrm{CO}_{2}$ electrolysis at extended time $(2 \mathrm{~h})$ is also conducted on $\mathrm{Ag}-\mathrm{Cu}$ and bare $\mathrm{Ag}$ surfaces (Supplementary Fig. 8). The $\mathrm{CH}_{4}$ formation is stable in the first hour with an FE of approximately $60 \%$. After that, the $\mathrm{CH}_{4} \mathrm{FE}$ gradually increases to $67 \%$ at the end of the $2-\mathrm{h}$ electrolysis, which is accompanied by the concomitant decrease of $\mathrm{CO}$ and $\mathrm{C}_{2} \mathrm{H}_{4} \mathrm{FE}$. The further increase in $\mathrm{CH}_{4} \mathrm{FE}$ is likely due to the surface reconstruction of $\mathrm{Cu}$ under $\mathrm{CO}_{2}$ electroreduction conditions that favors $\mathrm{CH}_{4}$ formation ${ }^{46,47}$. Further development of more advanced $\mathrm{Ag}-\mathrm{Cu}$ catalysts combining $\mathrm{Cu}$ and $\mathrm{Ag}$ with optimized material structure is a promising approach to achieve better performance in $\mathrm{CO}_{2} \mathrm{RR}$.

Operando spectroscopic investigations. To gain further insights into the $\mathrm{CO}$ spillover on the Ag- $\mathrm{Cu}$ surface, operando ATRSEIRAS is employed to monitor the adsorbed $\mathrm{CO}$ at conditions closely mimicking those in the reactivity studies. Experiments on bare $\mathrm{Ag}$, bare $\mathrm{Cu}$, and $\mathrm{Ag}-\mathrm{Cu}$ surface $\left(1.5 \mathrm{ppm} \mathrm{Cu}^{2+}\right)$ at -0.4 $\mathrm{V}_{\mathrm{RHE}}$ are conducted in a custom-designed stirred spectroelectrochemical cell (Supplementary Fig. 9) ${ }^{48}$. The bare Ag 
surface in the ATR-SEIRAS study is prepared by electrochemical deposition of $\mathrm{Ag}$ film in a silver cyanide plating bath on an $\mathrm{Au}$ film that is chemically deposited onto the reflecting plane of a $\mathrm{Si}$ prism ${ }^{49,50}$. The $\mathrm{Ag}$-Cu surface is then prepared in the same fashion as in the reactivity study, i.e., by conducting the experiments in a $\mathrm{Cu}^{2+}$-containing bicarbonate on the $\mathrm{Ag}$ film. The bare $\mathrm{Cu}$ surface is prepared via the chemical deposition method ${ }^{51}$. The bare Ag surface exhibits a $\mathrm{C} \equiv \mathrm{O}$ stretching band at $2094 \mathrm{~cm}^{-1}$ (Fig. 5), which is typically attributed to $\mathrm{CO}$ molecule bound in an atop geometry ${ }^{52}$. The bare $\mathrm{Cu}$ surface shows two stretching bands of atop-bound CO in the $2000-2120 \mathrm{~cm}^{-1}$ range, with the 2088 and $2055 \mathrm{~cm}^{-1}$ bands being attributed to $\mathrm{CO}$ adsorption on defect sites and terraces sites, respectively ${ }^{51}$. This is also consistent with previous studies by Waegele et al. under similar electrolysis conditions ${ }^{53}$. The $2094 \mathrm{~cm}^{-1}$ band on the $\mathrm{Ag}-\mathrm{Cu}$ surface is identical to that of bare Ag surface, as the peak position and width are both identical. The deconvoluted $\mathrm{C} \equiv \mathrm{O}$ stretching band on surface $\mathrm{Cu}$ has a broad feature centered at $2048 \mathrm{~cm}^{-1}$, which is consistent with a previous report ${ }^{54}$. The difference between the $\mathrm{CO}$ adsorption feature on the bare $\mathrm{Cu}$ and the $\mathrm{Ag}-\mathrm{Cu}$ surface shows that the underlying Ag exerts an impact on the properties of $\mathrm{Cu}$. Remarkably, the Ag-Cu surface exhibits a band in the $1800-1900 \mathrm{~cm}^{-1}$ range, typically assigned to bridge CO with stronger binding strength, which is absent on both bare Ag and $\mathrm{Cu}$ surfaces ${ }^{55,56}$. This band is much more intense than the atop $\mathrm{CO}$ band, thus is the major $\mathrm{CO}$ species on the $\mathrm{Ag}$ - $\mathrm{Cu}$ surface according to Beer-Lambert law. The spectroscopic observations clearly indicate that the Ag-Cu surface is different from a simple superposition of bare $\mathrm{Cu}$ and $\mathrm{Ag}$ surfaces. This is consistent with our one-pot tandem catalysis theory that the ${ }^{\star} \mathrm{CO}$ produced on the exposed Ag sites can migrate to stronger binding sites on the $\mathrm{Ag}-\mathrm{Cu}$ surface for further reduction. In addition, the exclusive band on the $\mathrm{Ag}-\mathrm{Cu}$ surface is not due to some new reactive site existing on the Ag-Cu bimetallic interface. If this is the case, the $\mathrm{CO}$ produced on the exposed $\mathrm{Ag}$ sites on $\mathrm{Ag}$ - $\mathrm{Cu}$ will not be consumed by further reduction, and the $\mathrm{CO}$ production should be promoted at more negatively biased potential until masstransport limitation, similar as the case of bare Ag foil. This contradicts the experimental results shown in Fig. $4 \mathrm{~b}$, d.

Constant and square-wave potential electrolysis of $\mathrm{CO}$ on the Ag-Cu surface. To further probe $\mathrm{CH}_{4}$ formation over $\mathrm{Ag}-\mathrm{Cu}$ surface with respect to local ${ }^{\star} \mathrm{CO}$ concentration, the electrochemical CO reduction reaction is conducted at $-1.1 \mathrm{~V}_{\mathrm{RHE}}$ using the same bicarbonate electrolyte, and the results are compared to those obtained using a bare $\mathrm{Cu}$ foil. At constant potential, the Ag$\mathrm{Cu}$ surface produces fewer hydrocarbons than the bare $\mathrm{Cu}$ foil in $\mathrm{CO}$ electrolysis (Fig. 6). This result can be rationalized that $\mathrm{Ag}$ is not active in $\mathrm{CO}$ electroreduction, thus fewer active $\mathrm{Cu}$ sites are present on the $\mathrm{Ag}-\mathrm{Cu}$ surface than on the $\mathrm{Cu}$ foil surface. Therefore, the observed enhancement of $\mathrm{CH}_{4}$ formation on the $\mathrm{Ag}-\mathrm{Cu}$ surface in $\mathrm{CO}_{2} \mathrm{RR}$ is apparently due to the tandem chemistry between $\mathrm{Ag}$ and $\mathrm{Cu}$.

In $\mathrm{CO}_{2} \mathrm{RR}, \mathrm{CO}$ adsorption can be difficult because $\mathrm{CO}$ adsorbate is suggested to come from the transformation of radical anion $\mathrm{CO}_{2}^{-}$instead of direct $\mathrm{CO}$ adsorption ${ }^{57,58}$. In addition, the surface $\mathrm{CO}$ adsorption can also be negatively impacted by the near electrode cations that are attracted by electrostatic forces as the electrode potential is negatively biased during the electrolysis ${ }^{50}$. However, the near electrode cations can be effectively removed at a more positive potential (e.g., 0.4 $\mathrm{V}_{\mathrm{RHE}}$ ), and $\mathrm{CO}$ adsorption can be promoted ${ }^{50}$. Based on these insights, square-wave potential electrolysis (inset of Fig. 6) of CO is employed to probe the catalytic behavior of our $\mathrm{Ag}$-Cu surface with an increased local ${ }^{\star} \mathrm{CO}$ concentration. The potential is
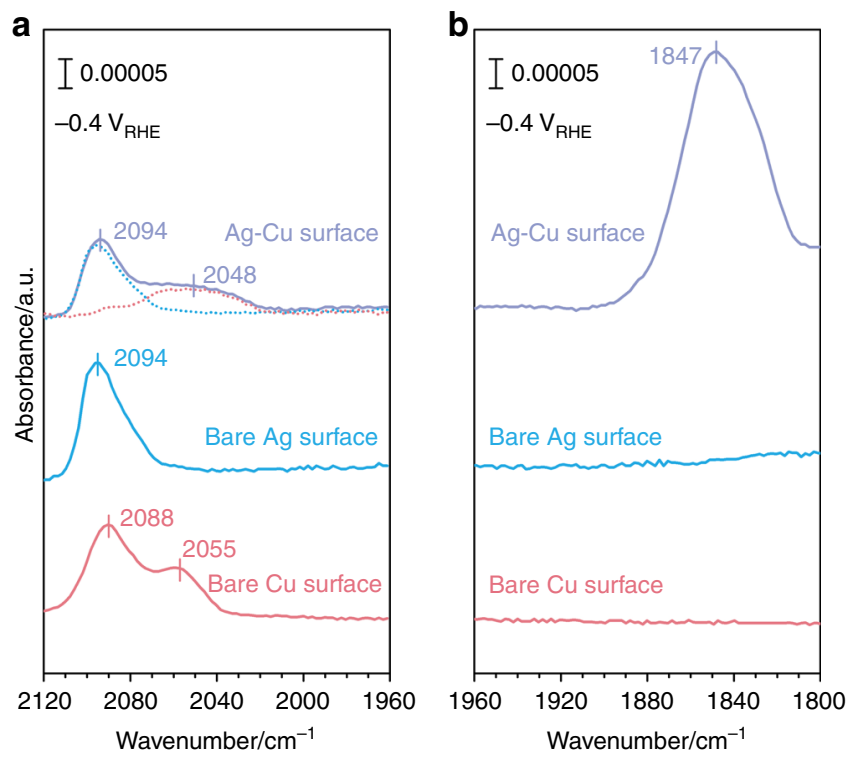

Fig. 5 Studies of surface-adsorbed $\mathrm{CO}$ on $\mathrm{Cu}$, bare $\mathrm{Ag}$ and $\mathrm{Ag}-\mathrm{Cu}$ films. Operando attenuated total reflectance surface enhanced infrared absorption spectroscopy (ATR-SEIRAS) of surface adsorption. a The atopbonded $\mathrm{CO}$ band on different surfaces under $-0.4 \mathrm{~V}_{\mathrm{RHE}}$. $\mathbf{b}$ The bridgebonded $\mathrm{CO}$ band on $\mathrm{Ag}-\mathrm{Cu}$ film under $-0.4 \mathrm{~V}_{\mathrm{RHE}}$. The background is collected at $0.1 \mathrm{~V}_{\mathrm{RHE}}$ under Ar purge

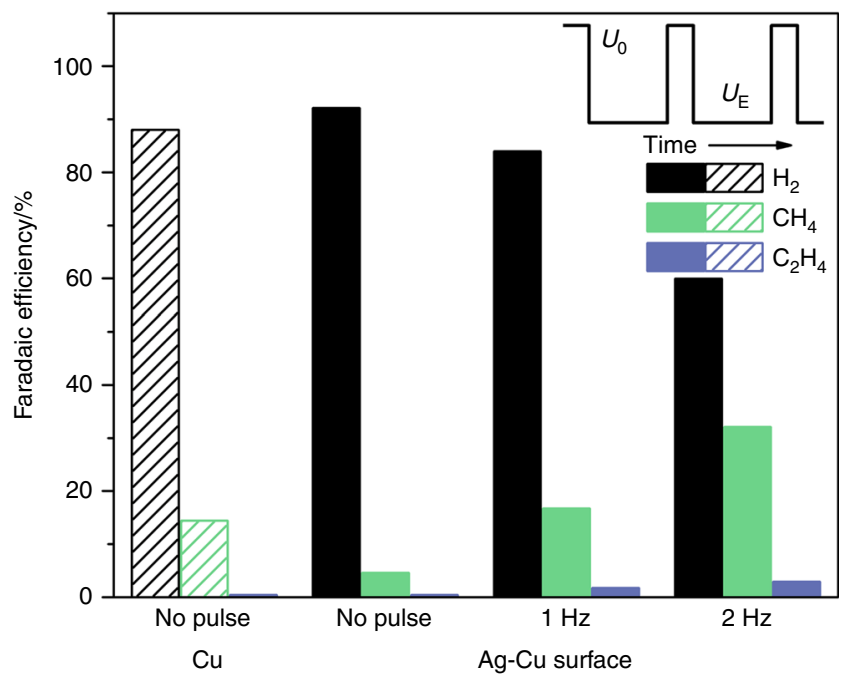

Fig. 6 Faradaic efficiencies of major carbon monoxide electroreduction products. Constant potential electrolysis at $-1.1 \mathrm{~V}_{\mathrm{RHE}}$ is conducted on the bare $\mathrm{Cu}$ and $\mathrm{Ag}$-Cu surfaces. Square-wave potential electrolysis alternating between $0.4 \mathrm{~V}_{\mathrm{RHE}}\left(U_{0}\right)$ and $-1.1 \mathrm{~V}_{\mathrm{RHE}}\left(U_{\mathrm{E}}\right)$ is conducted on the Ag-Cu surface. Inset: schematic representation of the square-wave potential profile employed in the electrolysis

alternated between $0.4 \mathrm{~V}_{\mathrm{RHE}}\left(U_{0}\right)$ for a fixed time interval of 0.01 $\mathrm{s}$, at which the $\mathrm{CO}$ adsorption is maximized ${ }^{50}$, and an electrolysis potential (i.e., $-1.1 \mathrm{~V}_{\mathrm{RHE}}, U_{\mathrm{E}}$ ) at which the $\mathrm{CO}$ reduction is expected to occur. By flipping the electrode potential at a frequency of approximately $1 \mathrm{~Hz}$, the $\mathrm{FE}$ toward hydrocarbon formation on the $\mathrm{Ag}-\mathrm{Cu}$ surface is significantly improved from $5 \%$ to $18 \%$, which surpassed that on a bare $\mathrm{Cu}$ surface. By increasing the frequency to approximately $2 \mathrm{~Hz}$, the FE toward hydrocarbon formation is further increased to $30 \%$, which is twice as high as that of bare $\mathrm{Cu}$. These results suggest that the increase of electrode ${ }^{\star} \mathrm{CO}$ concentration can efficiently improve 
the formation of further reduced products. The one-pot tandem catalysis mechanism that unitizes the complementary surface chemistry between a CO-producing material and $\mathrm{Cu}$ can be a very effective strategy for achieving this goal. However, to achieve more valuable products (e.g., $\mathrm{C}_{2+}$ products) requires further development employing more active CO-producing catalysts (e.g., nanoporous $\mathrm{Ag}^{4}$ or oxide-derived $\mathrm{Au}^{5}$ ) and $\mathrm{CO}$ reduction catalysts (e.g., oxide-derived $\mathrm{Cu}^{59,60}$ ) as well as their combination pattern and structure design for binding ${ }^{*} \mathrm{CO}$ to more desired sites after spillover.

\section{Discussion}

Density functional theory (DFT) calculations were carried out to investigate the one-pot tandem catalysis of the $\mathrm{CO}_{2} \mathrm{RR}$ on $\mathrm{Cu}$ modified $\mathrm{Ag}$ and $\mathrm{Au}$ surface models. We found that the surface $\mathrm{Cu}$ stabilized ${ }^{\star} \mathrm{CO}$ by 1.07 and $1.09 \mathrm{eV}$ compared to $\mathrm{Ag}$ and $\mathrm{Au}$, respectively, indicating that the abundant ${ }^{*} \mathrm{CO}$ produced on the $\mathrm{Ag}$ or $\mathrm{Au}$ surface can migrate to surface $\mathrm{Cu}$ for further reduction. We found that all reactions along the possible pathways are downhill under a potential bias of $-1.0 \mathrm{~V}_{\mathrm{SHE}}$, indicating that the migrated ${ }^{*} \mathrm{CO}$ from the Ag surface can be further reduced on the surface $\mathrm{Cu}$ with barriers that are not larger than those on a bare $\mathrm{Cu}$ surface. Electrochemical studies were conducted using welldefined $\mathrm{Ag}$ - $\mathrm{Cu}$ surfaces with tunable $\mathrm{Cu}$ coverages to confirm our computational predictions. The $\mathrm{CO}$ spillover phenomenon was experimentally demonstrated for the first time. At optimum $\mathrm{Cu}$ coverage, nearly $70 \%$ of the $\mathrm{CO}$ produced on $\mathrm{Ag}$ can be further reduced on surface $\mathrm{Cu}$, resulting in a high $\mathrm{CH}_{4} \mathrm{FE}$ of approximately $60 \%$. This $\mathrm{FE}$ is much higher than that on a bare $\mathrm{Cu}$ surface, which has intrinsically limited surface ${ }^{\star} \mathrm{CO}$. In addition, operando ATR-SEIRAS was employed to investigate the spillover of $\mathrm{CO}$ on the $\mathrm{Ag}-\mathrm{Cu}$ surface. A dominating $\mathrm{C} \equiv \mathrm{O}$ stretching band on the $\mathrm{Ag}-\mathrm{Cu}$ surface with stronger binding strength was found at $-0.4 \mathrm{~V}_{\mathrm{RHE}}$, which was absent on the bare $\mathrm{Ag}$ and $\mathrm{Cu}$ surface, suggesting that the major ${ }^{\star} \mathrm{CO}$ was not from $\mathrm{CO}_{2} \mathrm{RR}$ on $\mathrm{Cu}$. The stronger adsorption of ${ }^{*} \mathrm{CO}$ on $\mathrm{Cu}$ as compared to Ag strongly suggest the CO spillover as a viable pathway. Moreover, we conducted square-wave potential electrolysis of $\mathrm{CO}$ to assess the role of a higher ${ }^{*} \mathrm{CO}$ concentration on hydrocarbon formation over the Ag-Cu surface. By alternating the electrolysis potential between a reductive point and a point that removes the nearsurface cations, the FE for hydrocarbon formation was significantly enhanced owing to increased ${ }^{*} \mathrm{CO}$ adsorption. These results suggest that the increase of surface ${ }^{\star} \mathrm{CO}$ could efficiently improve the formation of further reduced products. We conclude that the one-pot tandem catalysis mechanism unitizing the complementary surface chemistry between a CO-producing material and $\mathrm{Cu}$ can be a very effective strategy for achieving this goal. Further development employing more active COproducing catalysts (e.g., nanoporous $\mathrm{Ag}^{4}$ or oxide-derived $\mathrm{Au}^{5}$ ) and $\mathrm{CO}$ reduction catalysts (e.g., oxide-derived $\mathrm{Cu}^{59,60}$ ) as well as their combination pattern and structure design provides a very promising route to achieve efficient $\mathrm{CO}_{2} \mathrm{RRs}$ toward more valuable products (e.g., $\mathrm{C}_{2+}$ products).

\footnotetext{
Methods

Computational details. The total energy of the $\mathrm{Cu}$-modified $\mathrm{Ag}(111)$ and $\mathrm{Au}(111)$ surfaces with different adsorbates were calculated using DFT with the PerdewBurke-Ernzerhof exchange-correlation functional ${ }^{61}$ in plane-wave pseudopotentials ${ }^{62,63}$, as implemented in the Vienna ab initio Simulation Package (VASP $^{64,65}$. The empirical $\mathrm{D}_{2}$ approach as implemented in VASP was employed to describe the van der Waals interactions ${ }^{66}$. All calculated energy values were extrapolated to $k_{\mathrm{B}} T=0$. A Monkhorst-Pack $k$-point net of $3 \times 6 \times 1$ was chosen to sample the reciprocal space for the slab calculations, and only the gamma point was sampled for the molecule calculations. A metal slab $(4 \times 2)$ consisting of 3 layers with the bottom layer fixed in its bulk position was employed to simulate the surface of $\mathrm{Ag}$ and $\mathrm{Au}$, and a single layer of $\mathrm{Cu}$ with a coverage of 1/2 ML
}

(monolayer) was placed on the substrate, as shown in Fig. 1a. A vacuum of $25 \AA$ was introduced to each side to avoid interactions between successive metal slabs. Coordinates of all calculation models are provided (Supplementary Note 1).

The transition state for each reaction was first approached using the nudged elastic band (NEB) method in the neutral state ${ }^{67}$. Forces on the climbing image were converged to $<0.02 \mathrm{eV}^{-1}$. The plane-wave cutoff, smearing parameter and functional, and calculator parameters were the same as those used in slab geometry optimizations. Structures obtained from NEB were employed to generate the input structure and orientation for the dimer calculation ${ }^{68}$. The force of the dimer calculation was converged to $<0.1 \mathrm{eV} \AA^{-1}$ to accurately locate the saddle point, i.e., the transition state. After that, the free energy of transition state was calculated under constant potential. An explicit water molecule was used as the proton source as previous work suggested ${ }^{38}$

To establish the electrochemical interface, the approach proposed by HeadGordon et al., Goddard et al., and Sautet et al. was applied ${ }^{37-39}$. In this model, the Fermi energy is adjusted to a target value by changing the number of electrons in the system during each step of the geometry optimization, which keeps the work function and electrode potential constant in the calculations. Then the linear Poisson-Boltzmann implicit solvation model with a Debye screening length of 3.0 $\AA$ was used to neutralize the non-zero charge in the simulation cell and simulate water and the electrolyte, allowing for a more realistic description of the electrochemical double layer. A detailed description of this approach has been provided in our previous work ${ }^{36}$

Electrolysis and product quantification. Ag foil (thickness $0.1 \mathrm{~mm}, 99.998 \%$ metal basis), Cu foil (thickness $0.1 \mathrm{~mm}, 99.9999 \%$ metal basis), Ti foil (thickness $0.127 \mathrm{~mm}, 99.99+\%$ metal basis), and $\mathrm{Ni}$ wire (99.9\%) were purchased from Alfa Aesar. A $5 \mathrm{~mm} \times 18 \mathrm{~mm}$ piece of $\mathrm{Ag}$ or $\mathrm{Cu}$ foil was used as the working electrode in the $\mathrm{CO}_{2}$ and $\mathrm{CO}$ electrolysis experiments. The Ag foil was mechanically polished using sand paper (1200 G, $3 \mathrm{M}$ ) and thoroughly cleaned in an ultrasonic bath with deionized water prior to electrolysis. The $\mathrm{Cu}$ foil was mechanically polished using sand paper (1200 G, $3 \mathrm{M}$ ) followed by electrochemical polishing in phosphoric acid ( 85 wt.\% in $\mathrm{H}_{2} \mathrm{O}$, Sigma-Aldrich, $99.99 \%$ metal basis) at $2.0 \mathrm{~V}$ vs a Ti foil counter electrode and thorough rinsing in fresh $0.1 \mathrm{M} \mathrm{NaHCO}_{3}$ solution to remove phosphoric acid residue prior to each experiment. Ni wires were welded to the edge of these $\mathrm{Ag}$ and $\mathrm{Cu}$ foil pieces as current collectors.

The $0.1 \mathrm{M} \mathrm{NaHCO}_{3}$ solution was prepared by dissolving $\mathrm{Na}_{2} \mathrm{CO}_{3}(99.999 \%$, Fluka) in deionized water that was obtained from a Millipore system $(18.2 \mathrm{M} \Omega \cdot \mathrm{cm})$ and converted to $\mathrm{NaHCO}_{3}$ using $\mathrm{CO}_{2}$ gas (99.99\%, Air Liquide). The electrolyte was treated using $\mathrm{Chelex}^{\circledast} 100$ resin (Sigma-Aldrich) prior to electrolysis. The 1 $\mathrm{mM} \mathrm{Cu}{ }^{2+}$ solution was prepared by dissolving $\mathrm{Cu}_{2} \mathrm{SO}_{4} \cdot 5 \mathrm{H}_{2} \mathrm{O}(99.999 \%$, SigmaAldrich) in $0.05 \mathrm{M}$ sulfuric acid (99.999\%, Sigma-Aldrich) according to a previously reported protocol ${ }^{43}$.

The $\mathrm{CO}_{2}$ electrolysis experiments were performed in a gas-tight twocompartment three-electrode electrochemical cell separated by a piece of a proton exchange membrane (Nafion ${ }^{\oplus}$ perfluorinated membrane). A graphite rod (99.999\%, Sigma-Aldrich) was used as the counter electrode. The cathodic compartment contained $18.0 \mathrm{~mL}$ of electrolyte and approximately $8.2 \mathrm{~mL}$ of headspace. Prior to electrolysis, the electrolyte in the cathodic compartment was purged with $\mathrm{CO}_{2}(99.99 \%$, Air Liquide) gas for at least $25 \mathrm{~min}$ until a $\mathrm{pH}$ of 6.8 was reached. Then the $\mathrm{Cu}^{2+}$ solution was added for the $\mathrm{Ag}-\mathrm{Cu}$ surface investigations. The electrolyte in the cathodic compartment was stirred at a rate of $800 \mathrm{rpm}$ during the electrolysis.

The CO electrolysis experiments were performed under identical conditions as the $\mathrm{CO}_{2}$ electrolysis experiments except for the gas feed. Prior to electrolysis, the electrolyte in the cathodic compartment was purged with CO (99.999\%, Air Liquide) gas rather than $\mathrm{CO}_{2}$ for at least $25 \mathrm{~min}$, and the $\mathrm{pH}$ was measured to be 8.4 .

The square-wave potential electrolysis was performed by alternating the potential between $0.4 \mathrm{~V}_{\mathrm{RHE}}\left(U_{0}\right)$ for a fixed time of $0.01 \mathrm{~s}$ and $-1.1 \mathrm{~V}_{\mathrm{RHE}}\left(U_{\mathrm{E}}\right)$ for 1 and $0.5 \mathrm{~s}$, which is equivalent to a frequency of approximately 1 and $2 \mathrm{~Hz}$, respectively. Only the cathodic charges were counted for the FE calculation. The charges from the capacitive current can be neglected owing to them being $<1 \%$ of the total cathodic charges.

A Gamry Reference $600+$ potentiostat was used for all electrolysis. All potentials were measured against a $\mathrm{Ag} / \mathrm{AgCl}$ reference electrode $(3.0 \mathrm{M} \mathrm{KCl}, \mathrm{BASi})$ and converted to the RHE reference scale using $\mathrm{E}(\mathrm{vs} \mathrm{RHE})=\mathrm{E}(\mathrm{vs} \mathrm{Ag} / \mathrm{AgCl})+$ $0.210 \mathrm{~V}+0.05916 \mathrm{~V} \times \mathrm{pH}$. The IR compensation function of the potentiostat was used to correct the electrode $\mathrm{Ru}$.

The gas products were quantified using a gas chromatograph (Agilent 7890B) The gas chromatograph was equipped with a ShinCarbon ST Micropacked GC Column. Argon (99.999\%, Air Liquide) was used as the carrier gas. First, the column effluent was passed through a thermal conductivity detector where the hydrogen was quantified. Then the effluent was passed through a methanizer where $\mathrm{CO}$ was converted to methane and subsequently quantified using a flame ionization detector.

The liquid products were quantified using a Bruker AVIII $400 \mathrm{MHz}$ NMR spectrometer. After electrolysis, $0.5 \mathrm{~mL}$ of the electrolyte was mixed with $0.1 \mathrm{~mL}$ of $\mathrm{D}_{2} \mathrm{O}$ (99.9\%, Sigma-Aldrich), and $1.67 \mathrm{ppm}(\mathrm{m} / \mathrm{m})$ dimethyl sulfoxide $(\geq 99.9 \%$, Alfa Aesar) was added as an internal standard. The ${ }^{1} \mathrm{H}$ spectrum was measured with water suppression using a presaturation method. 
Operando ATR-SEIRAS. $\mathrm{Al}_{2} \mathrm{O}_{3}, \mathrm{Na}_{2} \mathrm{~S}_{2} \mathrm{O}_{3}(98 \%), \mathrm{Na}_{2} \mathrm{SO}_{3}(98 \%), \mathrm{NaOH}(99.99 \%)$, $\mathrm{KOH}(99.99 \%), \mathrm{AgNO}_{3}$ (99\%), KCN (98\%), HCHO (37 wt.\%), HF (99\%),

$\mathrm{NaAuCl}_{4} \cdot 2 \mathrm{H}_{2} \mathrm{O}$ and $\mathrm{NH}_{4} \mathrm{Cl}$ were purchased from Sigma-Aldrich.

The Au substrate film for the Ag film was deposited directly on the reflecting plane of Si prism using a chemical deposition method ${ }^{50}$. Before depositing, $\mathrm{Si}$ prism was first polished with a slurry of $0.05 \mu \mathrm{m} \mathrm{Al}_{2} \mathrm{O}_{3}$ and sonicated in acetone (Fisher Chemical) and deionized water. After sonicating, the Si prism was dried with air and immersed in $\mathrm{NH}_{4} \mathrm{~F}$ (40\%, Sigma-Aldrich) for $120 \mathrm{~s}$ to create a hydrogen-terminated surface. Then the reflecting surface was immersed into a mixture of $0.8 \mathrm{~mL} \mathrm{HF}$ aqueous solution (2 wt.\%) and $4.4 \mathrm{~mL}$ Au plating solution consisting of $5.75 \mathrm{mM} \mathrm{NaAuCl} \cdot 2 \mathrm{H}_{2} \mathrm{O}, 0.025 \mathrm{M} \mathrm{NH}_{4} \mathrm{Cl}, 0.025 \mathrm{M} \mathrm{Na}_{2} \mathrm{~S}_{2} \mathrm{O}_{3} \cdot 5 \mathrm{H}_{2} \mathrm{O}$, $0.075 \mathrm{M} \mathrm{Na}_{2} \mathrm{SO}_{3}$, and $0.026 \mathrm{M} \mathrm{NaOH}$ for $10 \mathrm{~min}$. The temperature of the mixed solution was maintained at $55^{\circ} \mathrm{C}$ during the deposition. After the deposition, the $\mathrm{Au}$ film was rinsed with deionized water and dried with air.

The Ag film was electrodeposited on the Au substrate film potentiostatically in a typical three-electrode system using the Au film as the working electrode, a graphite rod as the counter electrode, and saturated $\mathrm{Ag} / \mathrm{AgCl}$ (BASi) as the reference electrode ${ }^{49}$. The electrolytic bath was prepared with deionized water and contained $0.15 \mathrm{M} \mathrm{AgNO}_{3}, 0.54 \mathrm{M} \mathrm{KCN}$, and $0.38 \mathrm{M} \mathrm{Na}_{2} \mathrm{CO}_{3}$. Electrodeposition in the prepared bath was carried out at $50 \mathrm{mV}_{\mathrm{RHE}}$ for $200 \mathrm{mC}$ at room temperature. Afterwards, the obtained Ag film was rinsed with deionized water and dried with air. The Ag-Cu surface was then prepared in the same fashion as in reactivity study, i.e., by conducting the experiments in a $\mathrm{Cu}^{2+}$-containing bicarbonate on the Ag film.

The $\mathrm{Cu}$ reference film directly deposited on the Si prism was prepared using a similar method as described previously ${ }^{51}$. Briefly, the polished Si prism was immersed in $\mathrm{NH}_{4} \mathrm{~F}$ for $60 \mathrm{~s}$ and then immersed into a copper seeding solution $(0.5$ wt.\% $\mathrm{HF}$ and $\left.750 \mu \mathrm{M} \mathrm{CuSO}_{4}\right)$ for $120 \mathrm{~s}$ followed by a plating solution $(0.25 \mathrm{M}$ HCHO, $0.02 \mathrm{M} \mathrm{CuSO}_{4}, 20 \mathrm{mM} \mathrm{Na} 2$ EDTA (99-101\%, ACS Reagent), and $0.3 \mathrm{mM}$ 2,2-bipyridine (99\%, Reagent Plus)) for $7 \mathrm{~min}$. The $\mathrm{pH}$ of the plating solution was adjusted to 12.2 by $\mathrm{KOH}$ and the temperature was maintained at $55^{\circ} \mathrm{C}$ during the deposition. Afterwards, the obtained $\mathrm{Cu}$ film was rinsed with deionized water and dried with air.

A two-compartment, three-electrode spectroelectrochemical cell, separated by a Nafion perfluorinated membrane, was designed to accommodate the Si prism and to avoid any possible cross-contamination from the counter electrode (Supplementary Fig. 9) ${ }^{48}$. $\mathrm{NaHCO}_{3} 0.1 \mathrm{M}$ was used as the electrolyte. The ATRSEIRAS experiments were conducted using an Agilent Technologies Cary 660 FTIR spectrometer equipped with a liquid nitrogen-cooled MCT detector. The spectrometer was coupled with a Solartron SI 1260/1287 system for electrochemical measurements. All spectra were collected at a $4 \mathrm{~cm}^{-1}$ spectral resolution and were presented in absorbance units. In a typical process, the obtained films on Si prisms were used as working electrodes with a graphite rod as the counter electrode and saturated $\mathrm{Ag} / \mathrm{AgCl}$ as the reference electrode.

Physical characterization. SEM images were recorded using a HITACHI S-5500 SEM. The accelerating voltage was $5 \mathrm{kV}$. TEM sample was prepared using $\mathrm{Ga}^{+}$ focused ion on a ZEISS AURIGA Field Emission-SEM implemented with CrossBeam ${ }^{\circ}$ Workstations. TEM images were recorded using a JEOL JEM-2010F TEM. The accelerating voltage was $200 \mathrm{kV}$. XPS measurements were carried out using a PHI Quantera II with $\mathrm{Al} \mathrm{Ka}$ radiation. The resulting spectra were analyzed using the CasaXPS software package (Casa Software Ltd., U.K.) and peaks were fit using a Gaussian/Lorentzian product line shape with the Shirley-type background.

\section{Data availability}

The data that support the findings of this study are available from the corresponding author upon request.

Received: 16 December 2018 Accepted: 30 June 2019

Published online: 26 July 2019

\section{References}

1. Centi, G., Quadrelli, E. A. \& Perathoner, S. Catalysis for $\mathrm{CO}_{2}$ conversion: a key technology for rapid introduction of renewable energy in the value chain of chemical industries. Energy Environ. Sci. 6, 1711-1731 (2013).

2. Lu, Q., Rosen, J. \& Jiao, F. Nanostructured metallic electrocatalysts for carbon dioxide reduction. Chem CatChem 7, 38-47 (2015).

3. Lu, Q. \& Jiao, F. Electrochemical $\mathrm{CO}_{2}$ reduction: electrocatalyst, reaction mechanism, and process engineering. Nano Energy 29, 439-456 (2016).

4. $\mathrm{Lu}, \mathrm{Q}$. et al. A selective and efficient electrocatalyst for carbon dioxide reduction. Nat. Commun. 5, 3242 (2014).

5. Chen, Y., Li, C. W. \& Kanan, M. W. Aqueous $\mathrm{CO}_{2}$ reduction at very low overpotential on oxide-derived Au nanoparticles. J. Am. Chem. Soc. 134, 19969-19972 (2012).
6. Chen, Y. \& Kanan, M. W. Tin oxide dependence of the $\mathrm{CO}_{2}$ reduction efficiency on tin electrodes and enhanced activity for tin/tin oxide thin-film catalysts. J. Am. Chem. Soc. 134, 1986-1989 (2012).

7. Verma, S., Lu, X., Ma, S., Masel, R. I. \& Kenis, P. J. The effect of electrolyte composition on the electroreduction of $\mathrm{CO}_{2}$ to $\mathrm{CO}$ on $\mathrm{Ag}$ based gas diffusion electrodes. Phys. Chem. Chem. Phys. 18, 7075-7084 (2016).

8. Kim, B., Hillman, F., Ariyoshi, M., Fujikawa, S. \& Kenis, P. J. A. Effects of composition of the micro porous layer and the substrate on performance in the electrochemical reduction of $\mathrm{CO}_{2}$ to CO. J. Power Sources 312, 192-198 (2016).

9. Hori, Y., Kikuchi, K. \& Suzuki, S. Production of $\mathrm{CO}$ and $\mathrm{CH}_{4}$ in electrochemical reduction of $\mathrm{CO}_{2}$ at metal electrodes in aqueous hydrogencarbonate solution. Chem. Lett. 14, 1695-1698 (1985).

10. Hori, Y., Kikuchi, K., Murata, A. \& Suzuki, S. Production of methane and ethylene in electrochemical reduction of carbon dioxide at copper electrode in aqueous hydrogencarbonate solution. Chem. Lett. 15, 897-898 (1986).

11. Kuhl, K. P., Cave, E. R., Abram, D. N. \& Jaramillo, T. F. New insights into the electrochemical reduction of carbon dioxide on metallic copper surfaces. Energy Environ. Sci. 5, 7050-7059 (2012).

12. $\mathrm{Li}, \mathrm{C} . \mathrm{W}$. \& Kanan, M. W. $\mathrm{CO}_{2}$ reduction at low overpotential on $\mathrm{Cu}$ electrodes resulting from the reduction of thick $\mathrm{Cu}_{2} \mathrm{O}$ films. J. Am. Chem. Soc. 134, 7231-7234 (2012).

13. Mariano, R. G., McKelvey, K., White, H. S. \& Kanan, M. W. Selective increase in $\mathrm{CO}_{2}$ electroreduction activity at grain-boundary surface terminations. Science 358, 1187-1192 (2017).

14. Mistry, H. et al. Highly selective plasma-activated copper catalysts for carbon dioxide reduction to ethylene. Nat. Commun. 7, 12123 (2016).

15. Gao, D. et al. Plasma-activated copper nanocube catalysts for efficient carbon dioxide electroreduction to hydrocarbons and alcohols. ACS Nano 11, 4825-4831 (2017).

16. De Luna, P. et al. Catalyst electro-redeposition controls morphology and oxidation state for selective carbon dioxide reduction. Nat. Catal. 1, 103-110 (2018).

17. Tang, W. et al. The importance of surface morphology in controlling the selectivity of polycrystalline copper for $\mathrm{CO}_{2}$ electroreduction. Phys. Chem. Chem. Phys. 14, 76-81 (2012).

18. Roberts, F. S., Kuhl, K. P. \& Nilsson, A. Electroreduction of carbon monoxide over a copper nanocube catalyst: surface structure and $\mathrm{pH}$ dependence on selectivity. ChemCatChem 8, 1119-1124 (2016).

19. Kim, D., Resasco, J., Yu, Y., Asiri, A. M. \& Yang, P. Synergistic geometric and electronic effects for electrochemical reduction of carbon dioxide using goldcopper bimetallic nanoparticles. Nat. Commun. 5, 4948 (2014).

20. Ren, D., Ang, B. S.-H. \& Yeo, B. S. Tuning the selectivity of carbon dioxide electroreduction toward ethanol on oxide-derived $\mathrm{Cu}_{\mathrm{x}} \mathrm{Zn}$ catalysts. ACS Catal. 6, 8239-8247 (2016).

21. Clark, E. L., Hahn, C., Jaramillo, T. F. \& Bell, A. T. Electrochemical $\mathrm{CO}_{2}$ reduction over compressively strained $\mathrm{CuAg}$ surface alloys with enhanced multi-carbon oxygenate selectivity. J. Am. Chem. Soc. 139, 15848-15857 (2017).

22. Morales-Guio, C. G. et al. Improved $\mathrm{CO}_{2}$ reduction activity towards $\mathrm{C}_{2+}$ alcohols on a tandem gold on copper electrocatalyst. Nat. Catal. 1, 764-771 (2018).

23. Hatsukade, T., Kuhl, K. P., Cave, E. R., Abram, D. N. \& Jaramillo, T. F. Insights into the electrocatalytic reduction of $\mathrm{CO}_{2}$ on metallic silver surfaces. Phys. Chem. Chem. Phys. 16, 13814-13819 (2014).

24. Rosen, J. et al. Mechanistic insights into the electrochemical reduction of $\mathrm{CO}_{2}$ to CO on nanostructured Ag surfaces. ACS Catal. 5, 4293-4299 (2015).

25. Peterson, A. A., Abild-Pedersen, F., Studt, F., Rossmeisl, J. \& Nørskov, J. K. How copper catalyzes the electroreduction of carbon dioxide into hydrocarbon fuels. Energy Environ. Sci. 3, 1311-1315 (2010).

26. Peterson, A. A. \& Nørskov, J. K. Activity descriptors for $\mathrm{CO}_{2}$ electroreduction to methane on transition-metal catalysts. J. Phys. Chem. Lett. 3, 251-258 (2012).

27. Li, J. et al. Effectively increased efficiency for electroreduction of carbon monoxide using supported polycrystalline copper powder electrocatalysts. ACS Catal. 9, 4709-4718 (2019).

28. Montoya, J. H., Peterson, A. A. \& Nørskov, J. K. Insights into C-C coupling in $\mathrm{CO}_{2}$ electroreduction on Copper electrodes. ChemCatChem 5, 737-742 (2013).

29. Montoya, J. H., Shi, C., Chan, K. \& Nørskov, J. K. Theoretical insights into a $\mathrm{CO}$ dimerization mechanism in $\mathrm{CO}_{2}$ electroreduction. J. Phys. Chem. Lett. 6 , 2032-2037 (2015)

30. Sandberg, R. B., Montoya, J. H., Chan, K. \& Nørskov, J. K. CO-CO coupling on Cu facets: coverage, strain and field effects. Surf. Sci. 654, 56-62 (2016).

31. Zhang, Y.-J., Sethuraman, V., Michalsky, R. \& Peterson, A. A. Competition between $\mathrm{CO}_{2}$ reduction and $\mathrm{H}_{2}$ evolution on transition-metal electrocatalysts. ACS Catal. 4, 3742-3748 (2014). 
32. Poelsema, B., Verheij, L. K. \& Comsa, G. He-scattering investigation of CO migration on $\mathrm{Pt}(111)$. Phys. Rev. Lett. 49, 1731-1735 (1982).

33. Klein, R. Adsorption, diffusion, and evaporation of carbon monoxide on tungsten. J. Chem. Phys. 31, 1306-1313 (1959).

34. Shi, C., Chan, K., Yoo, J. S. \& Nørskov, J. K. Barriers of electrochemical $\mathrm{CO}_{2}$ reduction on transition metals. Org. Process Res. Dev. 20, 1424-1430 (2016).

35. Cheng, T., Xiao, H. \& Goddard, W. A. 3rd Full atomistic reaction mechanism with kinetics for $\mathrm{CO}$ reduction on $\mathrm{Cu}(100)$ from ab initio molecular dynamics free-energy calculations at 298 K. Proc. Natl Acad. Sci. USA 114, 1795-1800 (2017).

36. Zhang, H., Goddard, W. A. 3rd, Lu, Q. \& Cheng, M. J. The importance of grand-canonical quantum mechanical methods to describe the effect of electrode potential on the stability of intermediates involved in both electrochemical $\mathrm{CO}_{2}$ reduction and hydrogen evolution. Phys. Chem. Chem. Phys. 20, 2549-2557 (2018).

37. Steinmann, S. N., Michel, C., Schwiedernoch, R., Filhol, J. S. \& Sautet, P. Modeling the $\mathrm{HCOOH} / \mathrm{CO}_{2}$ electrocatalytic reaction: when details are key. ChemPhysChem 16, 2307-2311 (2015).

38. Xiao, H., Cheng, T., Goddard, W. A. 3rd \& Sundararaman, R. Mechanistic explanation of the $\mathrm{pH}$ dependence and onset potentials for hydrocarbon products from electrochemical reduction of $\mathrm{CO}$ on $\mathrm{Cu}$ (111). J. Am. Chem. Soc. 138, 483-486 (2016).

39. Goodpaster, J. D., Bell, A. T. \& Head-Gordon, M. Identification of possible pathways for $\mathrm{C}-\mathrm{C}$ bond formation during electrochemical reduction of $\mathrm{CO}_{2}$ : new theoretical insights from an improved electrochemical model. J. Phys. Chem. Lett. 7, 1471-1477 (2016)

40. Garza, A., Bell, A. T. \& Head-Gordon, M. On the mechanism of $\mathrm{CO}_{2}$ reduction at copper surfaces: pathways to $\mathrm{C}_{2}$ products. ACS Catal. 8, 1490-1499 (2018).

41. Liu, X. et al. Understanding trends in electrochemical carbon dioxide reduction rates. Nat. Commun. 8, 15438 (2017).

42. Liu, X. et al. pH effects on the electrochemical reduction of $\mathrm{CO}_{(2)}$ towards $\mathrm{C}_{2}$ products on stepped copper. Nat. Commun. 10, 32 (2019).

43. Dietterle, M., Will, T. \& Kolb, D. The initial stages of copper deposition on Ag (111): an STM study. Surf. Sci. 342, 29-37 (1995).

44. Nikolić, N. D., Pavlović, L. J., Krstić, S. B., Pavlović, M. G. \& Popov, K. I. Influence of ionic equilibrium in the $\mathrm{CuSO}_{4}-\mathrm{H}_{2} \mathrm{SO}_{4}-\mathrm{H}_{2} \mathrm{O}$ system on the formation of irregular electrodeposits of copper. Chem. Eng. Sci. 63, 2824-2828 (2008).

45. Orhan, G. \& Gezgin, G. Effect of electrolysis parameters on the morphologies of copper powder obtained at high current densities. J. Serb. Chem. Soc. 77, 651-665 (2012).

46. Kim, Y. G., Baricuatro, J. H., Javier, A., Gregoire, J. M. \& Soriaga, M. P. The evolution of the polycrystalline copper surface, first to $\mathrm{Cu}(111)$ and then to $\mathrm{Cu}$ (100), at a fixed $\mathrm{CO}_{2} \mathrm{RR}$ potential: a study by operando EC-STM. Langmuir 30, 15053-15056 (2014).

47. Kim, Y.-G. et al. Surface reconstruction of pure-Cu single-crystal electrodes under CO-reduction potentials in alkaline solutions: A study by seriatim ECSTM-DEMS. J. Electroanal. Chem. 780, 290-295 (2016).

48. Dunwell, M. et al. Examination of near-electrode concentration gradients and kinetic impacts on the electrochemical reduction of $\mathrm{CO}_{2}$ using surfaceenhanced infrared spectroscopy. ACS Catal. 8, 3999-4008 (2018).

49. Wanzenböck, H. D., Mizaikoff, B., Weissenbacher, N. \& Kellner, R. Surface enhanced infrared absorption spectroscopy (SEIRA) using external reflection on low-cost substrates. Fresenius J. Anal. Chem. 362, 15-20 (1998).

50. Dunwell, M. et al. The Central role of bicarbonate in the electrochemical reduction of carbon dioxide on gold. J. Am. Chem. Soc. 139, 3774-3783 (2017).

51. Malkani, A. S., Dunwell, M. \& Xu, B. Operando spectroscopic investigations of copper and oxide-derived copper catalysts for electrochemical CO reduction. ACS Catal. 9, 474-478 (2019).

52. Ikezawa, Y., Saito, H., Matsubayashi, H. \& Toda, G. Comparative study of CO adsorbed on $\mathrm{Pt}, \mathrm{Pd}, \mathrm{Au}$ and $\mathrm{Ag}$ electrodes in neutral solution by IR reflection absorption spectroscopy. J. Electroanal. Chem. Inter. 252, 395-402 (1988).

53. Gunathunge, C. M. et al. Spectroscopic observation of reversible surface reconstruction of copper electrodes under $\mathrm{CO}_{2}$ reduction. J. Phys. Chem. C 121, 12337-12344 (2017)

54. Heyes, J., Dunwell, M. \& Xu, B. $\mathrm{CO}_{2}$ reduction on $\mathrm{Cu}$ at low overpotentials with surface-enhanced in situ spectroscopy. J. Phys. Chem. C 120, 17334-17341 (2016).

55. Gunathunge, C. M., Ovalle, V. J., Li, Y., Janik, M. J. \& Waegele, M. M. Existence of an electrochemically inert $\mathrm{CO}$ population on $\mathrm{Cu}$ electrodes in alkaline pH. ACS Catal. 8, 7507-7516 (2018).

56. Pérez Gallent, E., Figueiredo, M. C., Calle-Vallejo, F. \& Koper, M. T. M. Spectroscopic observation of a hydrogenated CO dimer intermediate during $\mathrm{CO}$ reduction on $\mathrm{Cu}(100)$ electrodes. Angew. Chem. Int. Ed. 129, 3675-3678 (2017).

57. Kortlever, R., Shen, J., Schouten, K. J. P., Calle-Vallejo, F. \& Koper, M. T. M. Catalysts and reaction pathways for the electrochemical reduction of carbon dioxide. J. Phys. Chem. Lett. 6, 4073-4082 (2015).
58. Genovese, C., Ampelli, C., Perathoner, S. \& Centi, G. Mechanism of C-C bond formation in the electrocatalytic reduction of $\mathrm{CO}_{2}$ to acetic acid. A challenging reaction to use renewable energy with chemistry. Green. Chem. 19, 2406-2415 (2017).

59. Li, C. W., Ciston, J. \& Kanan, M. W. Electroreduction of carbon monoxide to liquid fuel on oxide-derived nanocrystalline copper. Nature 508, 504-507 (2014)

60. Wang, Y., Raciti, D. \& Wang, C. High-flux CO reduction enabled by threedimensional nanostructured copper electrodes. ACS Catal. 8, 5657-5663 (2018).

61. Perdew, J. P., Burke, K. \& Ernzerhof, M. Generalized gradient approximation made simple. Phys. Rev. Lett. 77, 3865 (1996).

62. Blöchl, P. E. Projector augmented-wave method. Phys. Rev. B 50, 17953-17979 (1994).

63. Kresse, G. \& Joubert, D. From ultrasoft pseudopotentials to the projector augmented-wave method. Phys. Rev. B 59, 1758-1775 (1999).

64. Kresse, G. \& Hafner, J. Ab initio molecular dynamics for liquid metals. Phys. Rev. B 47, 558-561 (1993).

65. Kresse, G. \& Furthmüller, J. Efficient iterative schemes for ab initio totalenergy calculations using a plane-wave basis set. Phys. Rev. B 54, 11169-11186 (1996).

66. Grimme, S. Semiempirical GGA-type density functional constructed with a long-range dispersion correction. J. Comput. Chem. 27, 1787-1799 (2006).

67. Henkelman, G. \& Jónsson, H. Improved tangent estimate in the nudged elastic band method for finding minimum energy paths and saddle points. J. Chem. Phys. 113, 9978-9985 (2000).

68. Henkelman, G. \& Jónsson, H. A dimer method for finding saddle points on high dimensional potential surfaces using only first derivatives. J. Chem. Phys. 111, 7010-7022 (1999).

\section{Acknowledgements}

This work is supported by the National Key Research and Development Program of China (grant number 2017YFA0208200) and the National Natural Science Foundation of China (grant numbers 21872079, 21606142). W.A.G. is supported by the Joint Center for Artificial Photosynthesis, a DOE Energy Innovation Hub, supported through the Office of Science of the U.S. Department of Energy under Award Number DE-SC0004993. X.C and B.X. acknowledge the support of the National Science Foundation CAREER Program (Award No. CBET-1651625). M.-J.C. acknowledges financial support from the Ministry of Science and Technology of the Republic of China under grant no. MOST 107-2113M-006-008-MY2.

\section{Author contributions}

H.Z., M.-J.C., and Q.L. conceived and designed both computational and electrochemical investigations and wrote the manuscript. H.Z. and M.-J.C. performed DFT calculations and analyzed the data. H.Z. and Q.L. carried out the electrocatalytic tests and analyzed the results. H.Z. and Q.L. performed electron microscopy studies, FIB, XPS, and analyzed these data. X.C. and B.X. performed ATR-SEIRAS experiments and analyzed the results. J.G.C., W.A.G., and B.X. contributed to data analysis and writing of this manuscript.

\section{Additional information}

Supplementary Information accompanies this paper at https://doi.org/10.1038/s41467019-11292-9.

\section{Competing interests: The authors declare no competing interests.}

Reprints and permission information is available online at http://npg.nature.com/ reprintsandpermissions/

Peer review information: Nature Communication would like to thank the anonymous reviewers for their contribution to the peer review of this work.

Publisher's note: Springer Nature remains neutral with regard to jurisdictional claims in published maps and institutional affiliations.

Open Access This article is licensed under a Creative Commons Attribution 4.0 International License, which permits use, sharing, adaptation, distribution and reproduction in any medium or format, as long as you give appropriate credit to the original author(s) and the source, provide a link to the Creative Commons license, and indicate if changes were made. The images or other third party material in this article are included in the article's Creative Commons license, unless indicated otherwise in a credit line to the material. If material is not included in the article's Creative Commons license and your intended use is not permitted by statutory regulation or exceeds the permitted use, you will need to obtain permission directly from the copyright holder. To view a copy of this license, visit http://creativecommons.org/ licenses/by/4.0/.

(C) The Author(s) 2019 